\title{
ORIGINAL
}

\section{CASOS DE INFECCIÓN POR GRIPE PANDÉMICA (H1N1) 2009 HOSPITALIZADOS EN CUIDADOS INTENSIVOS EN ESPAÑA: FACTORES ASOCIADOS A RIESGO DE MUERTE, ABRIL 2009-ENERO 2010}

\begin{abstract}
Patricia Santa-Olalla Peralta, Marta Cortes García, Aurora Limia Sánchez, Josefa Andrés Prado, Isabel Pachón del Amo y Ma José Sierra Moros, en nombre del Subcomité de Vigilancia Epidemiológica del Plan Nacional de Preparación y Respuesta ante una Pandemia de Gripe.
\end{abstract}

Centro de Coordinación de Alertas y Emergencias Sanitarias (CCAES), Dirección General de Salud Pública y Sanidad Exterior, Ministerio de Sanidad y Política Social.

\section{RESUMEN}

Fundamento: El análisis de los casos graves de gripe pandémica es necesario para identificar grupos de población vulnerables y adecuar las políticas de prevención y control. Se analizan las características clínicas y epidemiológicas así como los factores asociados a riesgo de muerte en los casos de infección por virus pandémico (H1N1) 2009 hospitalizados en unidades de cuidados intensivos (UCI) en España y notificados entre el 24 de abril de 2009 y el 31 de enero de 2010.

Métodos: En el marco de la estrategia nacional de vigilancia de casos hospitalizados por gripe pandémica, se recogió a nivel nacional información clínica y epidemiológica individualizada de todos los casos hospitalizados en UCI por infección por virus pandémico (H1N1) 2009.

Resultados: De los 1.231 casos ingresados en una UCI fallecieron 271 (letalidad: 22\%). La mediana de edad fue 40 años (rango: 0-90). Un total de $838(76,3 \%)$ pacientes presentaban alguna patología subyacente, siendo la respiratoria la más frecuente $(34,1 \%)$, seguida en adultos de la obesidad mórbida $(18,8 \%)$. Un $93,1 \%$ recibió tratamiento antiviral y un $25,6 \%$ $(n=231)$ lo recibió en 48 horas desde el inicio de síntomas. En el análisis multivariante el cáncer (OR 2,71; IC95\% 1,44-5,1), las inmunodeficiencias (OR 2,25; IC95\% 1,29-3,92) y la obesidad mórbida (OR 1,79; IC95\% 1,132,85 ) estaban asociados significativamente a muerte en los adultos.

Conclusiones: La caracterización de los casos graves de gripe pandémica ha sido clave para identificar como factores de riesgo para sufrir complicaciones y muerte por gripe, la existencia de cáncer e inmunodeficiencias y, por primera vez, la obesidad mórbida en personas adultas.

Palabras clave: Pandemia. Subtipo H1N1 del Virus de la Influenza A. Gripe humana. España. Vigilancia poblacional. Unidad de Cuidados Intensivos Mortalidad. Obesidad. Factor de riesgo. Fallecimiento. Complicaciones. Neoplasias

\section{Correspondencia:}

Patricia Santa-Olalla Peralta

Centro de Coordinación de Alertas y Emergencias Sanitarias (CCAES)

Dirección General de Salud Pública y Sanidad Exterior

Ministerio de Sanidad y Política Social

Paseo del Prado, $\mathrm{n}^{\circ} 18-20$

28071 Madrid.

psantaolalla@msps.es

\section{ABSTRACT}

\section{Critically ill patients with 2009} pandemic influenza $A(H 1 N 1)$ infection in Spain: Factors associated with death, April 2009-January 2010

Background: It is necessary to analyse the severe cases of pandemic influenza infection in order to identify vulnerable populations and adapt prevention and control policies accordingly. We analysed the clinical and epidemiological characteristics and risk factors associated with death in patients with 2009 pandemic influenza A (H1N1) infection hospitalised in intensive care units (ICUs) in Spain and reported from 24 April 2009 to 31 January 2010.

Methods: As part of the national strategy for surveillance of hospitalized cases with pandemic influenza, cased-based clinical and epidemiological information on all cases admitted to an ICU with 2009 pandemic virus (H1N1) infection was collected nationwide.

Results: Of 1,231 cases admitted to ICU, 271 died (case fatality ratio, $22 \%$ ). The median age was 40 years (range: $0-90)$. A total of $838(76.3 \%)$ patients had an underlying risk condition, being respiratory disease the most frequently reported $(34.1 \%)$, followed by morbid obesity $(18.8 \%)$, in adults. Antiviral treatment was given in $93.1 \%$ patients and in $25.6 \%(\mathrm{n}=$ 231 ) it was initiated within 48 hours of symptoms onset. In a multivariate analysis, cancer (OR 2.71, 95\%CI 1.44 to 5.1), immunodeficiency (OR $2.25,95 \%$ CI $1.29-3.92$ ) and morbid obesity (OR $1.79,95 \%$ CI 1.13 to 2.85 ) were significantly associated with death in adults.

Conclusions: The characterization of severe pandemic influenza cases has been crucial in identifying as risk factors of complications and death from influenza the presence of cancer and immunodeficiencies and for the first time, morbid obesity in adults.

Key words: Pandemic. Influenza A Virus, H1N1 Subtype. Spain. Population surveillance. Intensive Care Unit. Obesity. Risk factor. Death. Complications. Neoplasm. 


\section{INTRODUCCIÓN}

El 25 de abril de 2009 la Organización Mundial de la Salud (OMS) calificó el brote por el nuevo virus de gripe $\mathrm{A}(\mathrm{H} 1 \mathrm{~N} 1)$ notificado previamente en los Estados Unidos ${ }^{1} \mathrm{y}$ México $^{2}$ como Emergencia de Salud Pública de Importancia Internacional (ESPII) bajo el Reglamento Sanitario Internacional $(2005)^{3,4}$. El 11 de junio de 2009, la OMS anunció el inicio de la primera pandemia de gripe del siglo $\mathrm{XXI}^{5}$.

En España, el Subcomité de Vigilancia (SV) del Plan Nacional de Preparación y Respuesta ante una Pandemia de Gripe, coordinado por el Centro de Coordinación de Alertas y Emergencias Sanitarias (CCAES) del Ministerio de Sanidad y Política Social (MSPS), tras recibir la alerta sobre este brote el 24 de abril, adaptó la definición de caso del Plan Nacional de Preparación y Respuesta ante una Pandemia de Gripe ${ }^{6}$ e implementó una vigilancia individualizada especifica de casos de gripe pandémica en la comunidad $^{7}$, apoyada sobre la Red Nacional de Vigilancia Epidemiológica.

Ante la evolución de la situación epidemiológica en España (incremento en el número de casos con presentación de formas graves) y en el marco de la nueva fase de la OMS en la que se recomienda, entre otras, que se recoja información que permita evaluar la gravedad de la enfermedad a nivel nacional $^{8}$, el 17 de junio de 2009 el SV aprobó la actualización de la estrategia de vigilancia incluyendo una vigilancia específica de casos graves asociados a la infección por el virus pandémico (H1N1) 2009. Esta nueva estrategia fue aprobada por la Comisión de Salud Pública el 26 de junio de 2009. Las sucesivas revisiones, realizadas en función de la situación epidemiológica, fueron aprobadas el 28 de julio y el 9 de septiembre de 2009.

El seguimiento y caracterización de los casos graves y fallecidos de infección por el virus pandémico (H1N1) 2009 es una parte esencial de la monitorización de la evolución, epidemiología y gravedad de una pandemia. Además, el análisis de la información de los casos graves y fatales es clave para conocer cuáles son los grupos de población más vulnerables y adecuar las políticas y recomendaciones iniciales en relación al uso de antivirales, la vacunación, y estrategias de control no farmacológicas. En este sentido, los primeros datos de los que se dispuso en relación a los factores que aumentan el riesgo de morbi-mortalidad por gripe pandémica (H1N1) 2009 apuntaban a los mismos descritos para la gripe estacional ${ }^{9}$. Sin embargo, durante los primeros meses de la pandemia se planteó por primera vez que otras condiciones médicas como la obesidad mórbida podrían estar asociadas a una mayor gravedad de la gripe pandémica ${ }^{10-13}$.

Las características de los casos hospitalizados en España durante la pandemia y los factores de riesgo asociados a gravedad ya han sido descritos ${ }^{14}$.

El objetivo de este artículo es describir y analizar las características clínicas y epidemiológicas así como los factores asociados a riesgo de muerte de los casos de infección por el virus pandémico (H1N1) 2009 hospitalizados en unidades de cuidado intensivos (UCI) en España, y notificados al CCAES a través de la Red Nacional de Vigilancia Epidemiológica desde el 24 de abril de 2009 al 31 de enero de 2010.

\section{MATERIAL Y MÉTODOS}

\section{Estrategia de vigilancia}

Durante el mes de junio de 2009 se revisó y actualizó la estrategia de vigilancia de la infección por el virus pandémico (H1N1) 2009, con el objetivo de identificar las características clínico epidemiológicas de los casos graves. Esta nueva estrategia revisada centraba la vigilancia de la infección por el 
virus pandémico (H1N1) 2009 en la información proporcionada por: 1 . El sistema de vigilancia de gripe estacional (Sistema de Vigilancia de la Gripe en España); 2. La vigilancia de agrupaciones de casos de infección respiratoria aguda; 3 . El seguimiento de gripe o enfermedad respiratoria aguda a partir de las bases informatizadas de Atención Primaria y/o servicios de urgencia; 4. La vigilancia individualizada de casos hospitalizados y 5. La vigilancia individualizada de casos de gripe en la comunidad. Esta última se abandonó en la revisión de la estrategia aprobada el 28 de julio de 2009.

El 22 de enero de 2010 el SV acordó el cese de la notificación individualizada al MSPS de los nuevos casos graves a partir del 1 de febrero de 2010, que pasaron a notificarse semanalmente de forma agregada. Únicamente se mantuvo la notificación individualizada al MSPS de los casos fallecidos.

Posteriormente, el 22 de marzo de 2010 el SV acordó el cese, a partir del 1 de abril de 2010, de la notificación agregada semanal a nivel nacional de los nuevos casos hospitalizados por gripe pandémica, así como de la notificación individualizada de personas fallecidas. A partir de entonces sólo se mantendría la vigilancia de gripe basada en el Sistema de Vigilancia de la Gripe en España (SVGE), que incluye las redes de médicos centinela y la vigilancia virológica, y el análisis de la mortalidad general diaria.

\section{Población de estudio}

La población de estudio estaba constituida por las personas ingresadas desde el $24 \mathrm{de}$ abril de 2009 hasta el 31 de enero de 2010 en cualquier hospital de España, con infección por el virus pandémico (H1N1) 2009 confirmada por laboratorio. Los criterios clínicos de caso grave de gripe pandémica (H1N1) 2009 incluidos en la definición de caso inicial eran: neumonía (infección respiratoria grave) o muerte por una enfermedad respira- toria aguda de causa desconocida. A raíz de la aprobación de una estrategia específica para la vigilancia individualizada de casos hospitalizados, desde el 26 de junio de 2009 se consideró caso grave de infección por el virus pandémico (H1N1) 2009 a las personas que presentaran un cuadro clínico compatible con gripe y que: 1.Requirieran ingreso hospitalario por la gravedad del cuadro clínico (neumonía, fallo multiorgánico, shock séptico) o 2. Desarrollaran este cuadro durante su ingreso hospitalario por otro motivo. También se consideró caso grave cualquier persona con neumonía ingresada en UCI en ausencia de una causa conocida y que presentara confirmación por laboratorio de la presencia del virus pandémico $(\mathrm{H} 1 \mathrm{~N} 1)$ 2009.

En este estudio se definió como paciente crítico a aquellas personas para las que constara ingreso en una UCI pediátrica o de adultos en la ficha de notificación.

La confirmación por laboratorio se realizó en aquellos sujetos que cumplían los criterios clínicos arriba mencionados, mediante técnicas moleculares específicas para el virus pandémico (H1N1) 2009 (RT-PCR). Los casos fueron confirmados por el Centro Nacional de Microbiología (CNM) o por los laboratorios de microbiología designados por las CCAA.

\section{Recogida de datos}

Los Servicios de Epidemiología y/o Alertas de las CCAA recogieron la información sobre las personas que cumplían la definición de caso mediante un formulario de notificación que incluía variables demográficas, características clínicas, complicaciones y evolución de los casos, características epidemiológicas, factores de riesgo (incluyendo embarazo y ocupacionales) y tratamiento (Anexo 1). La revisión y análisis de la información se centralizó en el CCAES (MSPS). 
Se incluyeron como factores de riesgo todas las patologías crónicas y condiciones, como el embarazo, que constituían una indicación para la vacunación frente a la gripe estacional en España ${ }^{15,16}$. También se recogió información sobre hábito tabáquico, disfunción cognitiva e índice de masa corporal (IMC). Estas dos últimas variables se incluyeron basándose en datos epidemiológicos preliminares sobre la pandemia procedentes de otros países ${ }^{11,17,18}$. Para este análisis, sólo se incluye información sobre obesidad mórbida en adultos $(\mathrm{IMC}=40)$.

La evolución final incluía las siguientes opciones: recuperación, fallecimiento por gripe pandémica (H1N1) 2009 o fallecimiento por otra causa con infección por virus pandémico (H1N1) 2009. Los sujetos incluidos en esta última categoría fueron excluidos de este análisis.

\section{Análisis de los datos}

$\mathrm{El}$ análisis de los datos se ha realizado con Excel y el paquete estadístico SPSS v.17.0.

Se consideraron como casos pediátricos a aquellos sujetos cuya edad estaba por debajo de 15 años.

La información sobre cada condición de riesgo subyacente se analizó y se describió de forma independiente. Todas las proporciones se han calculado como porcentajes de los casos con información disponible. En el caso de la variable «embarazo» las proporciones se calcularon como porcentaje de mujeres embarazadas entre las pacientes en edad fértil (mujeres de 15 a 44 años). Se creó una nueva variable, «número de comorbilidades»», teniendo en cuenta el número de condiciones de riesgo subyacentes notificadas para cada paciente. Para este análisis la obesidad mórbida y la disfunción cognitiva se consideraron como posibles condiciones de riesgo, mientras que el hábito tabaquico no. Se consideró que un paciente no presen- taba comorbilidades cuando la información sobre todas las condiciones de riesgo subyacentes estaba completa y se notificaba como ausente. Si una o más condiciones de riesgo subyacentes se notificaban como presentes, la variable «número de comorbilidades» sería la suma de todas las condiciones subyacentes notificadas.

Para los cálculos de tiempos el día del ingreso hospitalario se consideró como el día «0». La duración de la estancia hospitalaria se calculó como el tiempo transcurrido desde el día 0 al día del alta o del fallecimiento.

Se realizó un análisis bivariante, independiente para el grupo de adultos y el de niños, con el fin de comparar los factores de riesgo entre los pacientes ingresados en una UCI que se recuperaron frente a los ingresados en una UCI que fallecieron. Se usó la prueba chi $^{2}$ de Mantel-Haenszel (o la prueba exacta de Fisher cuando era apropiado) para comparar las variables categóricas y la prueba de Wilcoxon para la comparación de variables continuas. Las pruebas estadísticas fueron bilaterales. Para analizar los factores asociados a riesgo de muerte entre los pacientes ingresados en UCI se emplearon modelos de regresión logística multivariante utilizando las variables que fueron significativas en el análisis bivariante $(p<0,05)$. La regresión logística multivariante se realizó sólo en el grupo de adultos.

\section{Aspectos éticos}

Tanto los protocolos de vigilancia como el formulario de notificación de casos fueron aprobados por la Comisión de Salud Pública del Ministerio de Sanidad y Política Social. Esta investigación formó parte de la respuesta de salud pública a la pandemia de gripe 2009, por lo que no se consideró necesaria una evaluación ética específica ni solicitar consentimiento informado. Los datos fueron anonimizados para su análisis. 


\section{RESULTADOS}

Del 24 de abril de 2009 al 31 de enero de 2010 se notificaron al CCAES un total de 4.307 casos hospitalizados en toda España por infección por virus pandémico (H1N1) 2009 confirmada por laboratorio. De ellos, $1.231(28,6 \%)$ requirieron ingreso en una Unidad de Cuidados Intensivos (UCI). En el período de estudio fallecieron 342 personas por gripe pandémica, de las cuales 271 $(79,2 \%)$ habían ingresado en una UCI. Dos pacientes fallecieron antes de ingresar en el hospital. Además, se notificaron 35 casos hospitalizados con infección confirmada por el virus pandémico, que fallecieron por otras causas.

A continuación se describen las características y evolución de los pacientes ingresados en UCI en función de su evolución final (recuperado o fallecido).

\section{Distribución temporal de los casos ingresados en UCI}

El primer caso notificado ingresado en UCI fue hospitalizado el 12 de junio de 2009 y el último el 27 de enero de 2010. El máximo número de ingresos hospitalarios se registró en la semana epidemiológica (SE) 46 (del 15 al 21 de noviembre de 2009), con una media de ingresos superior a 80 casos por semana entre las SE 43-47 (comprendidas entre el 25 de octubre y el 28 de noviembre de 2009) (figura 1).

\section{Características demográficas de los casos ingresados en UCI}

La mediana de edad de los pacientes que ingresaron en una UCI fue de 40 años (rango, 0 meses a 90 años). Hubo una diferencia significativa $(p<0,001)$ entre la mediana de edad de los que se recuperaron (39 años, ran-

Figura 1

Número de casos ingresados en UCI por el virus de la gripe A (H1N1) 2009 según semana de ingreso hospitalario y número de casos clínicos estimados*. España, Abril 2009- Enero 2010 (n=1.227)\#

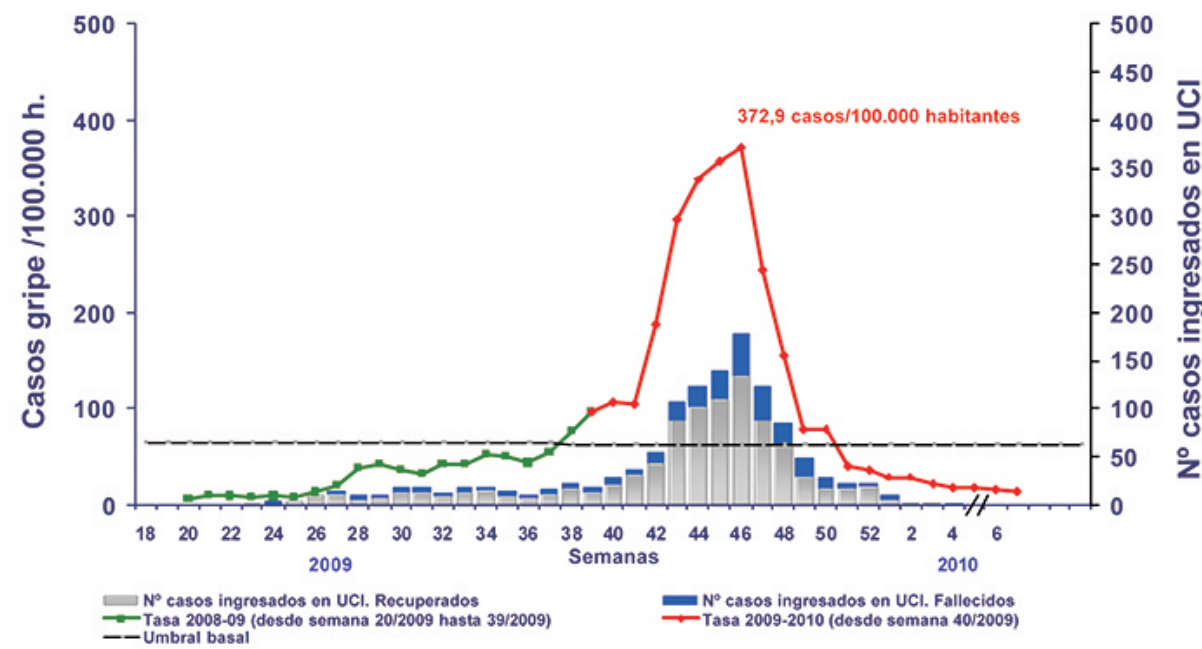

* Fuente: Sistema de Vigilancia de la Gripe en España (SVGE) ${ }^{24}$.

\# Se desconoce la información para 2 casos. 2 casos fallecidos no ingresan en el hospital. 
Figura 2

Distribución de casos ingresados en UCI por el virus de la gripe A (H1N1) 2009 por edad y evolución final.

España, Abril 2009- Enero $2010(n=1.230) *$

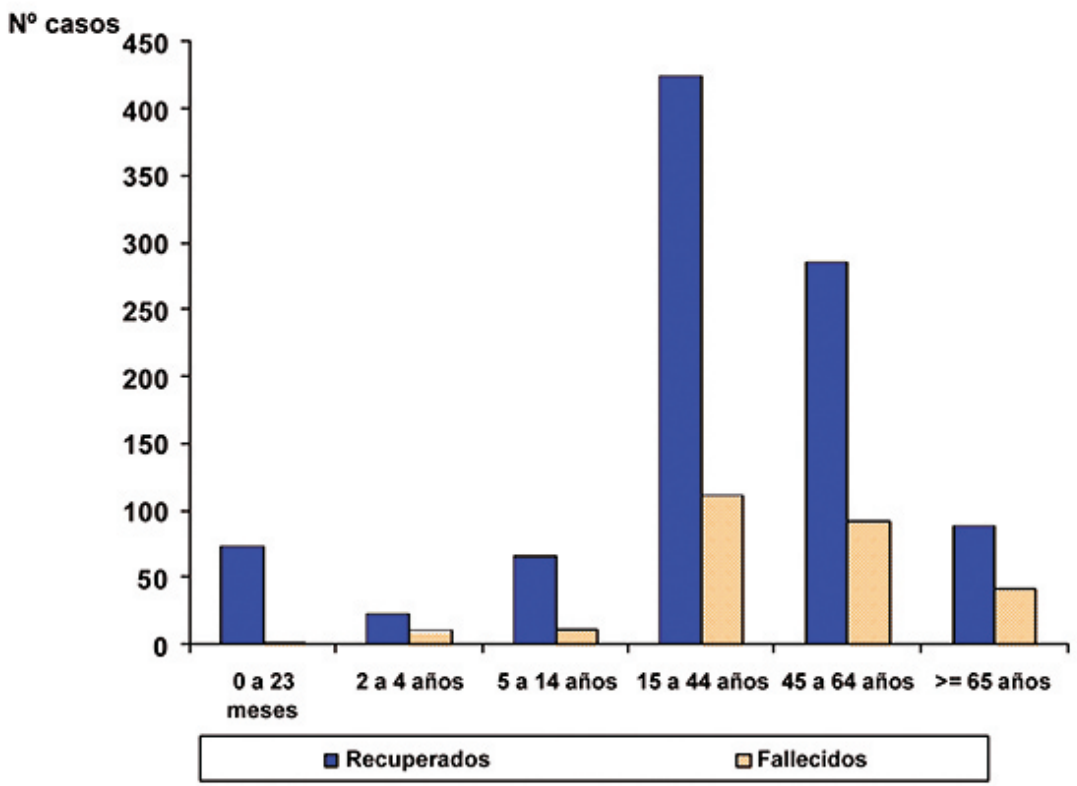

* Se desconoce la edad para un caso.

go de 0 a 90 años) y la mediana de edad de los que fallecieron (44,5 años, rango de 0 a 82 años). En total, 187 (15,2\%) pacientes eran menores de 15 años, y $130(10,6 \%)$ tenían 65 años o más. Los casos en menores de 2 años $(n=76)$ supusieron el 6,2\% del total de casos ingresados en UCI y el $40,6 \%$ de los casos pediátricos.

En la figura 2 puede observarse la distribución de los casos ingresados en UCI por grupo de edad y evolución final. De los 271 casos que fallecieron, el $8,9 \%$ era menor de 15 años y el 20,6\% tenía 65 años o más. La letalidad en los pacientes ingresados en UCI fue del $22 \%$. Se observó un aumento de la letalidad con la edad, siendo de $12,8 \%$ en menores de 15 años, $22,3 \%$ en los adultos entre 15-64 años y 32,3\% en los mayores de 64 años.
De 1.229 pacientes con información disponible $575(46,8 \%)$ eran mujeres, de las que 51 estaban embarazadas $(20,9 \%$ de las mujeres en edad fértil ingresadas en UCI). Una mujer embarazada tenía 14 años. La información sobre la duración de la gestación estaba disponible para 38 pacientes, 24 $(63,2 \%)$ estaban en el tercer trimestre y 11 en el segundo.

\section{Descripción de los factores de riesgo de los casos ingresados en UCI}

De los 1.098 pacientes con información disponible el $76,3 \%$ presentaba alguna condición de riesgo subyacente, siendo la patología respiratoria la notificada con más frecuencia. Como puede observarse en la figura 3, el número de patologías subyacentes y su prevalencia aumentaron con la 
Figura 3

Presencia de factores de riesgo por grupos de edad en los casos ingresados en UCI por el virus de la gripe A (H1N1) 2009. España, 24 Abril 2009- 31 Enero 2010 * \#

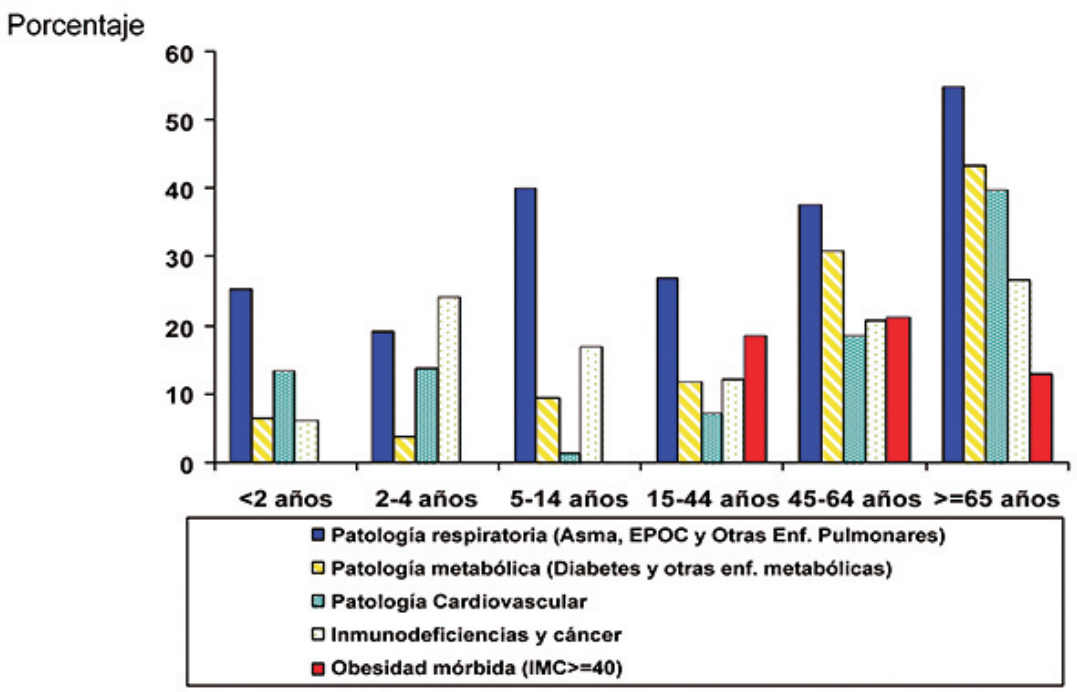

* Las condiciones enumeradas no son mutuamente excluyentes: algunos pacientes presentaron múltiples condiciones subyacentes

\# La distribución de las condiciones de riesgo fue significativamente diferente $(\mathrm{p}<0,001)$.

edad. De los pacientes mayores de 64 años el $93,9 \%$ de los que se recuperaron y el $100 \%$ de los fallecidos tenían patología de base.

Todas las condiciones de riesgo subyacentes se distribuían de forma diferente por grupos de edad $(\mathrm{p}<0,001)$. Debido a ello, su análisis se realizó por separado para adultos y menores de 15 años (tablas 1 y 2). Los pacientes ingresados en UCI que fallecieron tenían más edad, siendo la diferencia estadísticamente significativa, y presentaban más comorbilidades que aquellos que se recuperaron.

\section{Factores de riesgo en personas adultas}

En la tabla 1 se describen las características y condiciones subyacentes de las perso- nas adultas. En los 932 casos para los que se pudo determinar el número de comorbilidades, es de destacar que un $25,1 \%$ de los que se recuperaron no tenían ninguna condición de riesgo para complicaciones por gripe frente al $14 \%$ de los que fallecieron $(\mathrm{p}<0,001)$.

Las comorbilidades más frecuentes en los casos adultos ingresados en UCI fueron las patologías respiratorias, principalmente la EPOC. La segunda condición subyacente más frecuente en ambas categorías de pacientes fue la obesidad mórbida, si bien su prevalencia es significativamente superior en los pacientes fallecidos $(27,6 \%)$.

De 872 adultos con información disponible, $164(18,8 \%)$ presentaban obesidad mórbida. De los 104 pacientes con obesidad mórbida que se recuperaron $(27,9 \%)$ no presenta- 
Tabla 1

Características y condiciones subyacentes de los casos en adultos ingresados en UCI por infección por el virus de la gripe A (H1N1) 2009 según evolución final. España, 24 Abril 2009- 31 Enero 2010 (n=1.043)

\begin{tabular}{|c|c|c|c|}
\hline Características & $\begin{array}{c}\text { Pacientes } \\
\text { ingresados en UCI } \\
\text { que se recuperaron } \\
\text { n=797 } \\
\text { Porcentaje } \\
\text { (Número/Total) }^{\mathbf{a}, \mathbf{b}}\end{array}$ & $\begin{array}{c}\text { Pacientes } \\
\text { ingresados en UCI } \\
\text { que fallecieron } \\
\text { n=246 } \\
\text { Porcentaje } \\
\text { (Número/Total) }^{\mathbf{a}, \mathbf{b}}\end{array}$ & Valor $\mathbf{p}^{\mathrm{c}}$ \\
\hline Mediana de edad & 43 años (rango:15-90) & 47 años (rango:15-82) & $\mathrm{p}=0,002$ \\
\hline Sexo (mujer) & $48,6(387 / 796)$ & $44,1(108 / 245)$ & $\mathrm{p}=0,214$ \\
\hline Fumador actual & $39,2(231 / 589)$ & $31,5(58 / 184)$ & $\mathrm{p}=0,60$ \\
\hline Sin factores de riesgo & $25,1(175 / 697)$ & $14,0(33 / 235)$ & $\mathrm{p}<0,001$ \\
\hline Presencia de 2 o más factores de riesgo & $44,8(312 / 697)$ & $62,1(146 / 235)$ & $\mathrm{p}<0,001$ \\
\hline \multicolumn{4}{|l|}{ Condiciones subyacentes $^{d}$} \\
\hline Cualquier enf. pulmonar crónica & $34,0(230 / 677)$ & $36,8(77 / 209)$ & $\mathrm{p}=0,446$ \\
\hline - Asma & $13,7(87 / 635)$ & $12,5(25 / 200)$ & $\mathrm{p}=0,664$ \\
\hline - EPOC & $16,1(103 / 638)$ & $22,6(45 / 199)$ & $\mathrm{p}=0,037$ \\
\hline Obesidad mórbida $^{\mathrm{e}}$ & $15,9(104 / 655)$ & $27,6(60 / 217)$ & $\mathrm{p}<0,001$ \\
\hline Diabetes & $13,8(96 / 698)$ & $20,6(45 / 218)$ & $\mathrm{p}=0,014$ \\
\hline Otras enfermedades metabólicas & $10,8(66 / 611)$ & $14,3(27 / 189)$ & $\mathrm{p}=0,192$ \\
\hline Embarazo $^{f}$ & $21,8(41 / 188)$ & $17,6(9 / 51)$ & $\mathrm{p}=0,079$ \\
\hline Cáncer & $6,0(42 / 695)$ & $18,1(38 / 210)$ & $\mathrm{p}<0,001$ \\
\hline Inmunodeficiencias & $9,7(68 / 701)$ & $24,2(52 / 215)$ & $\mathrm{p}<0,001$ \\
\hline Enfermedad cardiovascular ${ }^{\mathrm{g}}$ & $14,7(103 / 702)$ & $19,4(42 / 217)$ & $\mathrm{p}=0,098$ \\
\hline Enfermedad hepática crónica & $7,2(44 / 614)$ & $14,1(27 / 192)$ & $\mathrm{p}=0,003$ \\
\hline Anemia o Hemoglobinopatía & $3,6(22 / 605)$ & $9,5(18 / 190)$ & $\mathrm{p}=0,001$ \\
\hline Disfunción cognitiva & $14,3(87 / 609)$ & $17,5(33 / 189)$ & $\mathrm{p}=0,286$ \\
\hline Trastornos convulsivos & $2,9(20 / 693)$ & $3,8(8 / 210)$ & $\mathrm{p}=0,499$ \\
\hline Insuficiencia renal crónica & $6,3(38 / 608)$ & $13,3(26 / 195)$ & $\mathrm{p}=0,001$ \\
\hline Asplenia & $0,7(4 / 606)$ & $0,5(1 / 190)$ & $\mathrm{p}=0,839$ \\
\hline Enfermedad neuromuscular & $2,6(16 / 606)$ & $4,8(9 / 187)$ & $\mathrm{p}=0,137$ \\
\hline Tratamiento con aspirina & $3,7(22 / 599)$ & $5,0(9 / 179)$ & $\mathrm{p}=0,416$ \\
\hline
\end{tabular}

UCI: Unidad de cuidados intensivos; EPOC: enfermedad pulmonar obstructiva crónica.

a Si no se indica lo contrario.

b El número indica el número de pacientes con la condición descrita. El total indica el total de pacientes con información disponible para esa condición.

c Comparación entre los pacientes recuperados y fallecidos en los pacientes que ingresaron en UCI.

d Las condiciones enumeradas no son mutuamente excluyentes: algunos pacientes presentaron múltiples condiciones subyacentes.

e Definida como índice de masa corporal igual o superior a 40. El índice de masa corporal se ha calculado como peso en kilogramos dividido por la altura en metros al cuadrado.

${ }^{f}$ Datos calculados utilizando como denominador el número de mujeres en edad fértil (15 a 44 años). Una mujer embarazada no se ha incluido por ser $<15$ años.

g Excluyendo hipertensión. 
Tabla 2

Características y condiciones subyacentes de los casos en menores de 15 años ingresados en UCI por infección por el virus de la gripe A (H1N1) 2009 según evolución final. España, 24 Abril 2009- 31 Enero 2010 (n=187)

\begin{tabular}{|c|c|c|c|}
\hline Características & $\begin{array}{c}\text { Pacientes } \\
\text { ingresados en UCI } \\
\text { que se recuperaron } \\
\text { n=163 } \\
\text { Porcentaje } \\
\text { (Número/Total) }^{\mathbf{a}, \mathbf{b}}\end{array}$ & $\begin{array}{c}\text { Pacientes } \\
\text { ingresados en UCI } \\
\text { que fallecieron } \\
n=24 \\
\text { Porcentaje } \\
\text { (Número/Total) }^{\text {a,b }}\end{array}$ & Valor $\mathbf{p}^{\mathrm{c}}$ \\
\hline Mediana de edad & 2 años (rango:0-14) & 5 años (rango:0-14) & $\mathrm{p}=0,003$ \\
\hline Sexo (mujer) & $44,2(72 / 163)$ & $29,2(7 / 24)$ & $\mathrm{p}=0,165$ \\
\hline Sin factores de riesgo & $34,5(49 / 142)$ & $13,0(3 / 23)$ & $\mathrm{p}=0,052$ \\
\hline Presencia de 2 o más factores de riesgo & $31,0(44 / 142)$ & $65,2(15 / 23)$ & $\mathrm{p}=0,001$ \\
\hline \multicolumn{4}{|l|}{ Condiciones subyacentes $^{d}$} \\
\hline Cualquier enf. pulmonar crónica & $29,8(42 / 141)$ & $38,9(7 / 18)$ & $\mathrm{p}=0,431$ \\
\hline - Asma & $19,5(26 / 133)$ & $12,5(2 / 16)$ & $\mathrm{p}=0,737$ \\
\hline - EPOC & $1,6(2 / 126)$ & $0(0 / 16)$ & $\mathrm{p}=0,999$ \\
\hline Diabetes & $2,9(4 / 140)$ & $0(0 / 19)$ & $\mathrm{p}=0,999$ \\
\hline Otras enfermedades metabólicas & $4,8(6 / 124)$ & $5,9(1 / 17)$ & $\mathrm{p}=0,990$ \\
\hline Cáncer & $7,2(10 / 139)$ & $42,1(8 / 19)$ & $\mathrm{p}<0,001$ \\
\hline Inmunodeficiencias & $8,1(11 / 136)$ & $26,3(5 / 19)$ & $\mathrm{p}=0,029$ \\
\hline Enfermedad cardiovascular ${ }^{\mathrm{e}}$ & $7,9(11 / 140)$ & $15,8(3 / 19)$ & $\mathrm{p}=0,379$ \\
\hline Enfermedad hepática crónica & $1,6(2 / 128)$ & $6,3(1 / 16)$ & $\mathrm{p}=0,300$ \\
\hline Anemia o Hemoglobinopatía & $3,2(4 / 126)$ & $11,8(2 / 17)$ & $\mathrm{p}=0,150$ \\
\hline Disfunción cognitiva & $17,9(22 / 123)$ & $31,3(5 / 16)$ & $\mathrm{p}=0,198$ \\
\hline Trastornos convulsivos & $15,1(21 / 139)$ & $42,9(9 / 21)$ & $\mathrm{p}=0,005$ \\
\hline Insuficiencia renal crónica & $2,4(3 / 123)$ & $5,6(1 / 18)$ & $\mathrm{p}=0,425$ \\
\hline Asplenia & $1,6(2 / 126)$ & $0(0 / 15)$ & $\mathrm{p}=0,999$ \\
\hline Enfermedad neuromuscular & $7,9(10 / 126)$ & $23,5(4 / 17)$ & $\mathrm{p}=0,065$ \\
\hline Tratamiento con aspirina & $1,6(2 / 125)$ & $0(0 / 15)$ & $\mathrm{p}=0,999$ \\
\hline
\end{tabular}

UCI: Unidad de cuidados intensivos; EPOC: enfermedad pulmonar obstructiva crónica.

a Si no se indica lo contrario.

b El numero indica el numero de pacientes con la condición descrita. El total indica el total de pacientes con información disponible para esa condición.

c Comparación entre los pacientes recuperados y fallecidos en los pacientes que ingresaron en UCI.

d Las condiciones enumeradas no son mutuamente excluyentes: algunos pacientes presentaron múltiples condiciones subyacentes.

e Excluyendo hipertensión.

ban otros factores de riesgo establecidos para gravedad por gripe. De los 60 pacientes con obesidad mórbida que fallecieron 18 (30\%) no tenían otra condición subyacente.

\section{Menores de 15 años}

En la tabla 2 se describen las características y condiciones subyacentes de los pacien- 
Tabla 3

Complicaciones presentadas en los casos ingresados en UCI con el virus de la gripe A (H1N1) 2009 según evolución final. España, 24 Abril 2009- 31 Enero $2010(n=1.231)^{\mathrm{a}}$

\begin{tabular}{|l|c|c|}
\hline \multicolumn{1}{|c|}{ COMPLICACIONES } & $\begin{array}{c}\text { Pacientes } \\
\text { ingresados en UCI } \\
\text { que se recuperaron } \\
\text { n=960 } \\
\text { Porcentaje } \\
\text { (Número/Total) }^{\mathbf{b}, \mathbf{c}}\end{array}$ & $\begin{array}{c}\text { Pacientes } \\
\text { ingresados en UCI } \\
\text { que fallecieron } \\
\text { n=271 } \\
\text { Porcentaje } \\
\text { (Número/Total) }\end{array}$ \\
\hline Neumonía & $80,6(719 / 892)$ & $88,0(228 / 259)$ \\
Hipoxemia & $91,4(751 / 822)$ & $98,8(246 / 249)$ \\
SDRA & $44,1(314 / 712)$ & $84,6(198 / 234)$ \\
Neumonía Secundaria & $35,7(169 / 473)$ & $50,9(83 / 163)$ \\
Shock & $20,6(139 / 676)$ & $64,9(133 / 205)$ \\
Sepsis & $27,3(186 / 682)$ & $58,4(125 / 214)$ \\
Alt. Función Hepática & $9,5(63 / 662)$ & $28,2(55 / 195)$ \\
Fracaso Renal Agudo & $13,2(91 / 689)$ & $52,8(112 / 212)$ \\
Alteraciones Cardiacas & $9,8(66 / 675)$ & $29,1(57 / 196)$ \\
CID & $3,1(21 / 677)$ & $18,3(37 / 202)$ \\
Fracaso Multiorgánico & $7,5(47 / 625)$ & $58,4(115 / 197)$ \\
\hline Ventilación mecánica & & $91,8(223 / 243)$ \\
Diálisis & $53,5(455 / 850)$ & $20,8(45 / 216)$ \\
\hline
\end{tabular}

UCI: Unidad de cuidados intensivos; SDRA: Síndrome de distress respiratorio agudo; CID: Coagulación intravascular diseminada.

a Todos los valores son significativos en el análisis bivariante $(\mathrm{p}<0.01)$.

b Si no se indica lo contrario.

c El numero indica el numero de pacientes con la complicación descrita. El total indica el total de pacientes con información disponible para esa complicación.

tes menores de 15 años. En 165 pacientes se pudo determinar el número de comorbilidades, de ellos un $34,5 \%$ de los que se recuperaron no tenían ninguna condición de riesgo frente al $13 \%$ de los que fallecieron.

La patología más frecuente en los casos pediátricos ingresados en UCI fue la respiratoria, principalmente asma. Otras comorbilidades notificadas con más frecuencia en los niños que se recuperaron fueron la disfunción cognitiva, los trastornos convulsivos, las inmunodeficiencias y la enfermedad neuromuscular. En el caso de los niños fallecidos destacan la presencia de trastornos convulsivos, cáncer, disfunción cognitiva, inmunode- ficiencias y enfermedad neuromuscular. En el análisis bivariante, la presencia de cáncer, las inmunodeficiencias y los trastornos convulsivos estaban significativamente asociados al riesgo de fallecimiento.

\section{Complicaciones de los casos ingresados en UCI}

Del conjunto de los pacientes ingresados en UCI un $82,3 \%$ (947 de 1.151 pacientes con datos disponibles) presentaron hallazgos radiológicos compatibles con neumonía viral primaria y un $93,1 \%$ (997 de 1.071 pacientes) presentaron hipoxemia. En un 
Tabla 4

Evolución de la enfermedad y tratamiento antiviral en los casos ingresados en UCI por el virus de la gripe A (H1N1) 2009 según evolución final. España, 24 Abril 2009- 31 Enero 2010 (n=1.231)

\begin{tabular}{|c|c|c|c|c|c|}
\hline & \multicolumn{2}{|c|}{$\begin{array}{c}\text { Pacientes } \\
\text { ingresados en UCI } \\
\text { que se recuperaron } \\
\text { n=960 }\end{array}$} & \multicolumn{2}{|c|}{$\begin{array}{c}\text { Pacientes } \\
\text { ingresados en UCI } \\
\text { que fallecieron } \\
\mathbf{n}=271\end{array}$} & \multirow[t]{2}{*}{ Valor $p^{c}$} \\
\hline & $\stackrel{\mathbf{N}^{\mathbf{0}}}{\text { pacientes }^{\mathrm{a}}}$ & $\begin{array}{l}\text { Mediana de } \\
\text { días }(\text { RIC) }\end{array}$ & $\underset{\text { pacientes }^{\mathbf{a}}}{\mathbf{N}^{\mathbf{0}}}$ & $\begin{array}{l}\text { Mediana de } \\
\text { días (RIC) }\end{array}$ & \\
\hline \multicolumn{6}{|l|}{ Evolución de la enfermedad } \\
\hline $\begin{array}{l}\text { Días desde inicio de síntomas } \\
\text { a hospitalización }\end{array}$ & 895 & $3(2-5)$ & 239 & $3(2-5)$ & $\mathrm{p}=0,585$ \\
\hline $\begin{array}{l}\text { Días desde hospitalización a ingreso } \\
\text { en UCI }\end{array}$ & 931 & $0(0-1)$ & 271 & $0(0-3)$ & $\mathrm{p}<0,001$ \\
\hline $\begin{array}{l}\text { Duración de la estancia } \\
\text { en el hospital }\end{array}$ & 812 & $16(10-27)$ & 239 & $12(6-22)$ & $\mathrm{p}<0,001$ \\
\hline Duración de la estancia en UCI & 794 & $7(3-15,25)$ & 239 & $10(4-20)$ & $\mathrm{p}=0,008$ \\
\hline Duración de la enfermedad clínica & 838 & $20(13-33)$ & 259 & $17(10-26)$ & $\mathrm{p}<0,001$ \\
\hline \multicolumn{6}{|l|}{ Tratamiento antiviral } \\
\hline Pacientes con tratamiento antiviral & 904 & $93,7 \%$ & 254 & $90,9 \%$ & $\mathrm{p}=0,127$ \\
\hline $\begin{array}{l}\text { Pacientes con inicio de tratamiento } \\
\text { antiviral en las primeras } 48 \mathrm{~h}\end{array}$ & 706 & $26,8 \%$ & 198 & $21,2 \%$ & $\mathrm{p}=0,113$ \\
\hline $\begin{array}{l}\text { Días desde inicio de síntomas } \\
\text { a inicio de tratamiento antiviral }\end{array}$ & 705 & $4(2-6)$ & 198 & $5(3-7)$ & $\mathrm{p}=0,110$ \\
\hline Días con tratamiento antiviral & 446 & $6(4-10)$ & 160 & $6(4-11)$ & $\mathrm{p}=0,430$ \\
\hline
\end{tabular}

UCI: Unidad de cuidados intensivos; RIC: rango intercuartílico.

a Numero de pacientes para los que esta información estaba recogida.

b Si no se indica lo contrario.

c Comparación de los pacientes recuperados y fallecidos entre los pacientes que ingresaron en UCI.

${ }^{\mathrm{d}}$ Excluyendo 49 casos que iniciaron síntomas después del ingreso hospitalario.

39,6\% (252 de 636 pacientes), se notificó una infección bacteriana secundaria. En la tabla 3 se presenta la distribución, según su evolución, de las complicaciones que tuvieron los pacientes ingresados en UCI. Entre los pacientes que fallecieron, las más frecuentes fueron el síndrome de distrés respiratorio agudo, shock, sepsis, fracaso multiorgánico y fracaso renal agudo.

\section{Evolución y tratamiento antiviral de los casos ingresados en UCI}

En la tabla 4 se describe la evolución temporal de la enfermedad y el tratamiento anti- viral en los casos ingresados en UCI según su evolución final. El intervalo de tiempo transcurrido desde el inicio de los síntomas al ingreso hospitalario fue similar entre los pacientes que se recuperaron y los que fallecieron, con una mediana de 3 días. La mediana del tiempo transcurrido desde la hospitalización al ingreso en UCI fue de menos de 24 horas para ambas categorías de pacientes, en el caso de los que fallecieron en este tiempo fue ligeramente superior. El fallecimiento de los pacientes que ingresaron en UCI se produce como mediana a los 17 días del inicio de la enfermedad clínica [rango intercuartílico (RIC): 10-26]. 
Del total de pacientes críticos un $93,1 \%$ (1.078 de 1.158) recibió tratamiento con fármacos antivirales. Un 25,6\% (231 de 904) de los pacientes recibió tratamiento dentro de las primeras 48 horas desde el inicio de los síntomas, sin que hubiera diferencias significativas entre los que se recuperaron y los que fallecieron (tabla 4). El porcentaje de pacientes que recibió tratamiento fue mayor en el grupo de adultos que en el de niños $(94,2 \%$ vs $86,9 \%, p=0,002)$.

\section{Análisis multivariante}

Se realizó un análisis multivariante para el grupo de adultos que incluyó edad, sexo, EPOC, obesidad mórbida, diabetes, cáncer, inmunodeficiencias, enfermedad hepática crónica, anemia o hemoglobinopatía e insuficiencia renal crónica. Las variables que se asociaron significativamente con el fallecimiento fueron el cáncer (OR 2,71; IC 95\% $1,44-5,1 ; \mathrm{p}=0,002)$, las inmunodeficiencias (OR 2,25; IC 95\% 1,29-3,92; $\mathrm{p}=0,004)$, y la obesidad mórbida (OR 1,79; IC 95\% 1,13$2,85 ; \mathrm{p}=0,013)$.

\section{DISCUSIÓN}

Los resultados que se presentan constituyen la serie más larga publicada hasta la fecha en España de pacientes hospitalizados en UCI por complicaciones de la infección por el virus pandémico (H1N1) 2009, incluyendo 1.231 pacientes de los que fallecieron 271 durante el período de estudio.

La vigilancia epidemiológica de la gripe pandémica se puso en marcha en abril de 2009, tras la alerta de la $\mathrm{OMS}^{19}$, pero no fue hasta la mitad de junio de 2009 que comenzó a registrarse el ingreso hospitalario de los primeros casos graves, coincidiendo con un aumento en el número de casos en la comunidad $^{7}$. El máximo número de ingresos se registró a mitad de noviembre, coincidiendo con la incidencia máxima de casos en la población española ${ }^{20}$.
A diferencia de lo que ocurre con la gripe estacional, como ya se ha descrito para esta pandemia $^{12,21-23}$, la mayoría de los pacientes hospitalizados en UCI eran jóvenes y adultos de mediana edad. Sin embargo, es de destacar la alta proporción de adultos mayores de 64 años $(10,6 \%)$ entre los casos ingresados en UCI y entre los que fallecieron $(20,6 \%)$, teniendo en cuenta que los casos de gripe en la comunidad en este grupo de edad representaron sólo el 2,5\% de todos los casos en España (datos del Sistema de Vigilancia de la Gripe $)^{24}$. Además, la letalidad más alta también se registra en este grupo. Este hallazgo es consistente con los resultados de otros estudios ${ }^{13,25,26}$ y parece indicar que, si bien la incidencia de la infección ha sido menor en las personas mayores de 64 años, cuando ésta ha ocurrido ha sido más grave y letal. Esto puede ser debido al hecho de que la probabilidad de presentar una o más comorbilidades y su prevalencia aumenta con la edad, y sea esta presencia de patología crónica lo que se asocie a riesgo de muerte, independientemente de la edad.

Al igual que en la gripe estacional, la mayoría de los casos ingresados en UCI eran personas que presentaban condiciones de riesgo previas. Sin embargo, un $23,7 \%$ de los pacientes no tenían factores de riesgo, siendo mayor este porcentaje en los niños. Hay que resaltar que el 14\% de las personas adultas fallecidas y el 13\% de los niños fallecidos eran personas previamente sanas.

La distribución de las condiciones de riesgo fue diferente en los distintos grupos de edad. En los adultos las comorbilidades más frecuentes fueron la patología respiratoria (principalmente EPOC), la obesidad mórbida y las enfermedades cardiovasculares. Estos resultados están en consonancia con los resultados de estudios publicados de otros países ${ }^{12,13,22,27}$. Sin embargo, llama la atención la elevada prevalencia de la obesidad mórbida en los pacientes ingresados en UCI $(15,9 \%$ en los recuperados y $27,6 \%$ en los fallecidos) comparada con la prevalencia 
aproximada del $0,5 \%$ en la población adulta española ${ }^{28}$.

Entre las mujeres embarazadas, la mayoría se encontraban en el tercer trimestre de gestación, tal como ocurre con la gripe estacional dado el mayor riesgo de complicaciones por gripe al final del embarazo ${ }^{29}$.

En el análisis multivariado se identificó que la obesidad mórbida, las inmunodeficiencias y el cáncer son factores independientes de riesgo de muerte en los adultos. El hecho de que las inmunodeficiencias y el cáncer sean factores de riesgo de muerte por cualquier infección no es inesperado ${ }^{12,13,22}$. Durante esta pandemia se ha identificado un posible vínculo entre la obesidad, especialmente la mórbida, y la gravedad de la infección por gripe pandémica ${ }^{11-14,22}$. Sin embargo, nos gustaría destacar que este es uno de los pocos estudios ${ }^{30}$ donde se ha hallado que la obesidad mórbida es un factor de riesgo independiente para muerte por gripe pandémica (OR 1,79; IC 95\% 1,13-2,85). El 30\% de los pacientes con obesidad mórbida que fallecieron no tenían otros factores de riesgo.

En el caso de los niños, las patologías notificadas con más frecuencia fueron la respiratoria (principalmente asma), la disfunción cognitiva y los trastornos convulsivos. Estas dos últimas se habían descrito previamente asociadas a gravedad en niños con gripe pandémica en los EEUU ${ }^{12,18} \mathrm{y}$, recientemente, en los niños hospitalizados con gripe pandémica en España ${ }^{14}$. El pequeño número de niños fallecidos no ha permitido realizar un análisis multivariante de los factores de riesgo en este grupo de edad, por lo que se hacen necesarios más estudios. Sin embargo, los resultados obtenidos en nuestro análisis apuntan a una asociación entre los trastornos convulsivos y el fallecimiento.

Este análisis y el realizado sobre los casos hospitalizados en España ${ }^{14}$, han contribuido a la decisión de incluir a las personas con obesidad mórbida y disfunción cognitiva como grupos de riesgo y destinatarios de la vacunación frente a la gripe estacional para la próxima temporada 2010-11 en España ${ }^{16}$.

La mitad de los pacientes habían ingresado a los 3 días del inicio de los síntomas, presentando una rápida aparición de complicaciones, principalmente neumonía viral primaria e hipoxemia grave que requirió ventilación mecánica en la mayoría de los casos. Otras complicaciones incluyen el SDRA, sepsis y shock observadas en cerca del 50\% de los pacientes. Estos hallazgos son consistentes con los resultados de estudios en otros países $^{12,27,31}$.

Una alta proporción de pacientes $(93,1 \%)$ recibieron tratamiento antiviral. Sin embargo, sólo un $25,6 \%$ lo recibió en las primeras 48 horas desde el inicio de los síntomas, a pesar de que se recomienda su inicio de forma temprana en las personas pertenecientes a grupos de riesgo y en todos los casos hospitalizados. Las causas del retraso en el inicio del tratamiento antiviral deberían ser identificadas y tenidas en cuenta en futuros planes de respuesta. Los datos publicados de esta pandemia indican que el uso de antivirales puede reducir la gravedad y mortalidad por la gripe pandémica, sobre todo cuando este tipo de tratamiento se inicia temprano ${ }^{12,14,32}$.

Los resultados presentados tienen algunas limitaciones. Los datos se obtuvieron durante una alerta de salud pública y mediante un sistema de recogida de casos graves que hubo que implantar al inicio de la pandemia e ir adaptando en función de la evolución de la misma, por lo que es necesario hacer algunas consideraciones al respecto. En primer lugar, los datos fueron recogidos con fines de vigilancia epidemiológica, por lo que la información clínica y de las complicaciones presentadas no es exhaustiva. En segundo lugar, algunos datos están incompletos, hecho inherente a la vigilancia en brotes epidémicos. Esto puede haber afectado al análisis de la presencia de condiciones de riesgo 
en los pacientes, dado que hemos sido conservadores al considerar la ausencia de comorbilidades. Por ello, es posible que el porcentaje real de casos sin condiciones de riesgo para complicaciones por gripe sea superior al notificado $(25,1 \%$ y $34,5 \%$ respectivamente en adultos y niños recuperados). En tercer lugar, la notificación individualizada de casos al CCAES no ha sido igual de exhaustiva en todo el territorio español, en algunos casos debido a diferencias en la implementación de la estrategia de vigilancia en las diferentes CCAA. Sin embargo, basándonos en la información agregada notificada al CCAES sobre el total de casos confirmados hospitalizados en UCI y el total de casos fallecidos en cada Comunidad Autónoma, se estima que los casos analizados en este informe suponen el total de los pacientes ingresados en UCI que fallecieron, y en torno a un $70 \%$ de los ingresados en UCI que fueron capturados por el sistema de vigilancia implantado.

En conclusión, el seguimiento y caracterización de los casos graves de infección por el virus (H1N1) 2009 en nuestro país ha sido clave para caracterizar los grupos de población en riesgo de presentar complicaciones por gripe e identificar la obesidad mórbida como nuevo factor de riesgo de fallecimiento por gripe. La vigilancia de los casos graves ha jugado un papel fundamental en la toma de decisiones de las autoridades sanitarias, permitiendo adaptar las políticas y recomendaciones iniciales en relación a la vacunación, uso de antivirales y estrategias de control no farmacológicas.

\section{AGRADECIMIENTOS}

La realización de este artículo ha sido posible gracias a los numerosos compañeros de los Servicios de Salud Pública y Laboratorios de las CCAA que han contribuido con la vigilancia e investigación de casos de la gripe pandémica (H1N1) 2009. También agradecemos el trabajo y dedicación de los profesionales sanitarios del Sistema Nacional de Salud en toda España.

\section{BIBLIOGRAFÍA}

1. Centers for Disease Control and Prevention (CDC). Swine Influenza A(H1N1) infections - California and Texas, April 2009. MMWR Morb Mortal Wkly Rep. 2009; 58:(16):435-7. Disponible en: http:// www.cdc.gov/mmwr/preview/mmwrhtml/mm581 6a7.htm

2. Centers for Disease Control and Prevention (CDC). Outbreak of swine-origin influenza A (H1N1) virus infection-Mexico, March-April 2009. MMWR Morb Mortal Wkly Rep. 2009;58:467-470. Disponible en: http:// www.cdc.gov/mmwr/preview/ mmwrhtml/mm58d0430a2.htm.

3. World Health Organisation. International health regulations (2005). 2nd ed. 2008. Disponible en: http://www.who.int/ihr/9789241596664/en/index. html (citado el 22 julio 2010).

4. World Health Organisation. Swine influenza. Statement to the press by WHO Director-General Dr Margaret Chan. 25 April 2009. Disponible en: http://www.who.int/mediacentre/news/statements/2009/h1n1 20090425/en/index.html (citado el 22 julio 2010).

5. World Health Organisation. World now at the start of 2009 influenza pandemic. Statement to the press by WHO Director-General Dr Margaret Chan. 11 June 2009. Disponible en: http://www.who.int/ mediacentre/news/statements/2009/h1n1_pandemic_phase6_20090611/en/index.html (citado el 22 julio 2010).

6. Ministerio de Sanidad y Consumo. Plan Nacional de Preparación y Respuesta ante una Pandemia de Gripe. Mayo 2005. Disponible en: http:/www. msps.es/ciudadanos/enfLesiones/enfTransmisibles/pandemia/home.htm (citado el 22 julio 2010).

7. Santa-Olalla Peralta P, Cortes García M, Martínez Sánchez EV, Nogareda Moreno F, Limia Sánchez A, Pachón del Amo I, Sierra Moros MJ. Vigilancia individualizada de los casos iniciales de infección por gripe pandémica (H1N1) 2009 en España, Abril - Junio 2009. Rev Esp Salud Pública 2010; 84:529-46.

8. World Health Organisation. Global Surveillance during an Influenza Pandemic. Version 1.Updated draft April 2009. Disponible en: http://www.who. int/csr/resources/publications/swineflu/surveillance/en/index.html. 
9. World Health Organisation. Pandemic (H1N1) 2009 briefing note 4: Preliminary information important for understanding the evolving situation. 24 July 2009. Disponible en: http://www.who. int/csr/disease/swineflu/notes/h1n1_situation_20090724/en/index.html (citado el $\overline{2} 2$ julio $201 \overline{0})$.

10. World Health Organization. Pandemic (H1N1) 2009 briefing note 13: Clinical features of severe cases of pandemic influenza. 16 October 2009. Disponible en: http://www.who.int/csr/disease/swineflu/notes/h1n1_clinical_features_20091016/en/ind ex.html (citado el 22 julio 2010).

11. Centers for Disease Control and Prevention (CDC). Intensive-care patients with severe novel influenza A (H1N1) virus infection - Michigan, June 2009. MMWR Morb Mortal Wkly Rep. 2009;58(27):749-52. Disponible en: http://www. cdc.gov/mmwr/preview/mmwrhtml/mm5827a4.ht $\mathrm{m}$ (citado el 22 julio 2010).

12. Jain S, Kamimoto L, Bramley AM, Schmitz AM, Benoit SR, Louie J, et al. Hospitalised patients with 2009 H1N1 influenza in the United States, AprilJune 2009. N Engl J Med. 2009;361(20):1925-44.

13. Louie JK, Acosta M, Winter K, Jean C, Gavali S, Schechter R, et al. Factors associated with death or hospitalization due to pandemic 2009 influenza A(H1N1) infection in California. JAMA. 2009; 302(17):1896-902.

14. Santa-Olalla Peralta P, Cortes-García M, VicenteHerrero M, Castrillo-Villamandos C, Arias-Bohigas P, Pachon-del Amo I, Sierra-Moros MJ, on behalf of the Surveillance Group for New Influenza A(H1N1) Virus Investigation and Control Team in Spain. Risk factors for disease severity among hospitalised patients with 2009 pandemic influenza A (H1N1) in Spain, April - December 2009. Euro Surveill. 2010;15(38):pii=19667. Disponible en: http://www.eurosurveillance.org/ViewArticle.aspx ?ArticleId=19667.

15. Ministerio de Sanidad y Política Social. Vacunaciones en adultos. Recomendaciones año 2004. Madrid; 2004. Disponible en: http://www.msc. es/ciudadanos/proteccionSalud/vacunaciones/docs /recoVacunasAdultos.pdf (citado el 22 julio 2010).

16. Ministerio de Sanidad y Política Social. Prevención de la Gripe. Vacunación antigripal. Disponible en: http://www.msc.es/ciudadanos/enfLesiones/enfTransmisibles/gripe/gripe.htm\#prevencion.

17. Centers for Disease Control and Prevention (CDC). Hospitalised patients with novel influenza A (H1N1) virus infection - California, April-May 2009. MMWR Morb Mortal Wkly Rep. 2009;58(19):53641. Disponible en: http://www.cdc.gov/mmwr/preview/mmwrhtml/mm5819a6.htm.

18. Centers for Disease Control and Prevention (CDC). Surveillance for pediatric deaths associated with 2009 pandemic influenza A (H1N1) virus infection - United States, April-August 2009. MMWR Morb Mortal Wkly Rep. 2009;58(34):941-7. Disponible en: http://www.cdc.gov/mmwr/preview/ mmwrhtml/mm5834a1.htm.

19. World Health Organization. Influenza-like illness in the United States and Mexico. 24 April 2009. Disponible en: http:/www.who.int/csr/don/2009 _04_24/en/index.html.

20. Instituto de Salud Carlos III. Boletín semanal del Sistema de Vigilancia de la Gripe en España (SVGE). Semana 46/2009 (del 15 al 21 de noviembre de 2009). Disponible en: http://www.isciii.es/ htdocs/centros/epidemiologia/pdf/grn4609.pdf (citado el 22 julio 2010).

21. Health Protection Agency (HPA). Pandemic (H1N1) 2009 in England: an overview of initial epidemiological findings and implications for the second wave. v4. 2 Dec 2009. Disponible en: http://www.hpa.org.uk/web/HPAwebFile/HPAweb C/1258560552857.

22. Fuhrman C, Bonmarin I, Paty AC, Duport N, Chiron E, Lucas E, et al. Severe hospitalised 2009 pandemic influenza A(H1N1) cases in France, 1 July15 November 2009. Euro Surveill. 2010;15(2). pii: 19463. Disponible en: http://www.eurosurveillance.org/ViewArticle.aspx?ArticleId=19463.

23. van 't Klooster TM, Wielders CC, Donker T, Isken L, Meijer A, van den Wijngaard CC, et al. Surveillance of hospitalisations for 2009 pandemic influenza $\mathrm{A}(\mathrm{H} 1 \mathrm{~N} 1)$ in the Netherlands, 5 June - 31 December 2009. Euro Surveill 2010;15(2). pii: 19461. Disponible en: http://www.eurosurveillance.org/ViewArticle.aspx?ArticleId=19461.

24. Instituto de Salud Carlos III. Boletín semanal del Sistema de Vigilancia de la Gripe en España (SVGE). Semana 04/2010 (del 24 al 30 de enero de 2010). Disponible en: http://www.isciii.es/htdocs/ centros/epidemiologia/pdf/grn4909.pdf.

25. Donaldson LJ, Rutter PD, Ellis BM, Greaves FE, Mytton OT, Pebody RG, et al. Mortality from pandemic A/H1N1 2009 influenza in England: public health surveillance study. BMJ. 2009; 339:b5213. 
26. New South Wales public health network. Progression and impact of the first winter wave of the 2009 pandemic H1N1 influenza in New South Wales, Australia Euro Surveill. 2009;14(42). pii: 19365. Disponible en: http://www.eurosurveillance.org/ ViewArticle.aspx?ArticleId=19365.

27. Domínguez-Cherit G, Lapinsky SE, Macias AE, Pinto R, Espinosa-Perez L, de la Torre A, et al. Critically Ill patients with 2009 influenza A(H1N1) in Mexico. JAMA 2009;302(17):1880-7.

28. Aranceta J, Pérez Rodrigo C, Serra Majem L, Ribas Barba L, Quiles Izquierdo J, Vioque J, et al. Prevalencia de la obesidad en España: resultados del estudio SEEDO 2000. Med Clin (Barc). 2003; 120(16):608-12.

29. Dodds L, McNeil S, Fell D, Allen V, Coombs A, Scott J, MacDonald N. Impact on influenza exposure on rates of hospital admissions and physician visits because of respiratory illness among pregnant women. CMAJ 2007. 176: 463-468.

30. Cui W, Zhao H, Lu X, Wen Y, Zhou Y, Deng B et al. Factors associated with death in hospitalized pneumonia patients with 2009 H1N1 influenza in Shenyang, China. BMC Infect Dis. 2010 May 31; 10:145.

31. Kumar A, Zarychanski R, Pinto R, Cook DJ, Marshall J, Lacroix J, et al. Critically ill patients with 2009 influenza A(H1N1) infection in Canada. JAMA. 2009;302(17):1872-9.

32. Centers for Disease Control and Prevention (CDC). Updated interim recommendations for the use of antiviral medications in the treatment and prevention of influenza for the 2009-2010 season. 7 December 2009. Available from: http://www.cdc. gov/h1n1flu/recommendations.htm. 


\section{Anexo 1}

Ficha para la notificación de casos hospitalizados (03.08.2009)

\section{FORMULARIO DE NOTIFICACIÓN DE CASOS GRAVES DE}

\section{INFECCIÓN POR VIRUS PANDÉMICO (H1N1) 2009}

Fecha de Notificación:

Comunidad Autónoma:

Código':

$(\mathrm{dd} / \mathrm{mm} / \mathrm{aaaa})$

\section{Datos del paciente}

Iniciales del Paciente (Nombre y apellidos):

Sexo: Hombre $\square \quad$ Mujer $\square$

\section{Ingreso hospitalario}

Diagnóstico al ingreso:

Fecha de ingreso (dd/mm/aaaa):

¿lngresó en UCl? Sí $\square$ No $\square$ Desconocido $\square \quad$ Fecha de ingreso en UCl (dd/mm/aaaa):

\section{Factores intrínsecos del paciente}

\begin{tabular}{|c|c|c|c|c|}
\hline Fumador actual: & Sí $\square$ & No $\square$ & Desconocido $\square$ & \\
\hline Asma: & & Sí $\square$ & No $\square$ & Desconocido $\square$ \\
\hline EPOC: & Sí $\square$ & No $\square$ & Desconocido $\square$ & \\
\hline Otra enfermedad respiratoria crónica: & Sí $\square$ & No $\square$ & Desconocido $\square$ & \\
\hline
\end{tabular}

\footnotetext{
${ }^{1}$ Código: $X X Y Y Y Y\left(X X=\right.$ código CCAA; $Y Y Y Y=n^{\circ}$ de caso, ej: 010001)
} 
Especificar:

Insuficiencia renal:

Sí $\square \quad$ No $\square \quad$ Desconocido $\square$

Inmunodeficiencia activa:

(VIH,quimoterapia, tto esteroideo...) S

Sí $\square \quad$ No $\square \quad$ Desconocido $\square$

Cáncer (incluyendo leucemia, linfoma): Sí

No $\square \quad$ Desconocido $\square$

Enfermedad cardiovascular:

(excluye HTA):

Si $\square \quad$ No $\square \quad$ Desconocido $\square$

Enfermedad hepática crónica:

Sí $\square \quad$ No $\square$ Desconocido $\square$

Hemoglobinopatía y/o anemia:

Sí $\square \quad$ No $\square \quad$ Desconocido $\square$

Trastornos convulsivos:

Sí $\square \quad$ No $\square \quad$ Desconocido $\square$

Disfunción cognitiva:

Sí $\square \quad$ No $\square \quad$ Desconocido $\square$

$\square$ Demencias

Otros

$\begin{array}{llll}\text { Asplenia } & \text { Sí } \square & \text { No } \square & \text { Desconocido } \square \\ \text { Enfermedad Neuromuscular: } & \text { Sí } \square & \text { No } \square & \text { Desconocido } \square\end{array}$

Especificar:

Tratamiento prolongado con ácido acetilsalicílico: Sí $\square \quad$ No $\square \quad$ Desconocido $\square$

Otros:

Embarazo: Semanas de gestación:

$\begin{array}{lll}\text { Si } \square & \text { No } \square & \text { Desconocido } \square \\ \text { Si } \square & \text { No } \square & \text { Desconocido } \square\end{array}$

Clínica (presentada durante el proceso)

Fecha de Inicio de síntomas (dd/mm/aaaa):

Fiebre $\left(>38^{\circ} \mathrm{C}\right)$, especificar grados:

Sí $\square \quad$ No $\square \quad$ Desconocido $\square$

Tos

Sí $\square \quad$ No $\square \quad$ Desconocido $\square$

Cefalea:

Sí $\square$

No $\square$

Desconocido $\square$

Rinorrea:

Sí $\square$

No $\square$

Desconocido $\square$

Dolor de garganta:

Sí $\square \quad$ No $\square \quad$ Desconocido $\square$

Mialgia:

Sí $\square \quad$ No $\square \quad$ Desconocido $\square$

Dificultad respiratoria/ disnea:

Sí $\square \quad$ No $\square \quad$ Desconocido $\square$ 
Malestar general:

Diarrea

Vómitos:

Convulsiones:

Alteración de la conciencia:
Sí

Sí $\square$

Sí $\square$

Sí

Sí
No $\square$

No $\square$

No $\square$

No $\square$

No $\square$
Desconocido

Desconocido

Desconocido

Desconocido

Desconocido

Otros síntomas:

\begin{tabular}{|ccc|c|}
\hline Neumonía: Sí $\square$ No $\square$ Desconocido $\square$ & Fecha de diagnóstico de neumonía (dd/mm/aaaa): \\
¿Radiografía de tórax con signos de neumonía?:Sí $\square \quad$ No $\square \quad$ Desconocido $\square$ \\
$\square$ Consolidación: Si consolidación, especifique & Unilobar $\square \quad$ Multilobar $\square \quad$ Bilateral $\square$ \\
$\square$ Infiltrado intersticial & $\square$ Derrame pleural & $\square$ Neumotórax & \\
\hline
\end{tabular}

Neumonía primaria por influenza: S

Neumonía secundaria bacteriana S

Infección adquirida en el hospital: Sí $\square$ No $\square$

Desconocido

\section{Complicaciones*}

Complicaciones observadas durante el curso de la enfermedad: Sí $\square$ No $\square$ Desconocido $\square$

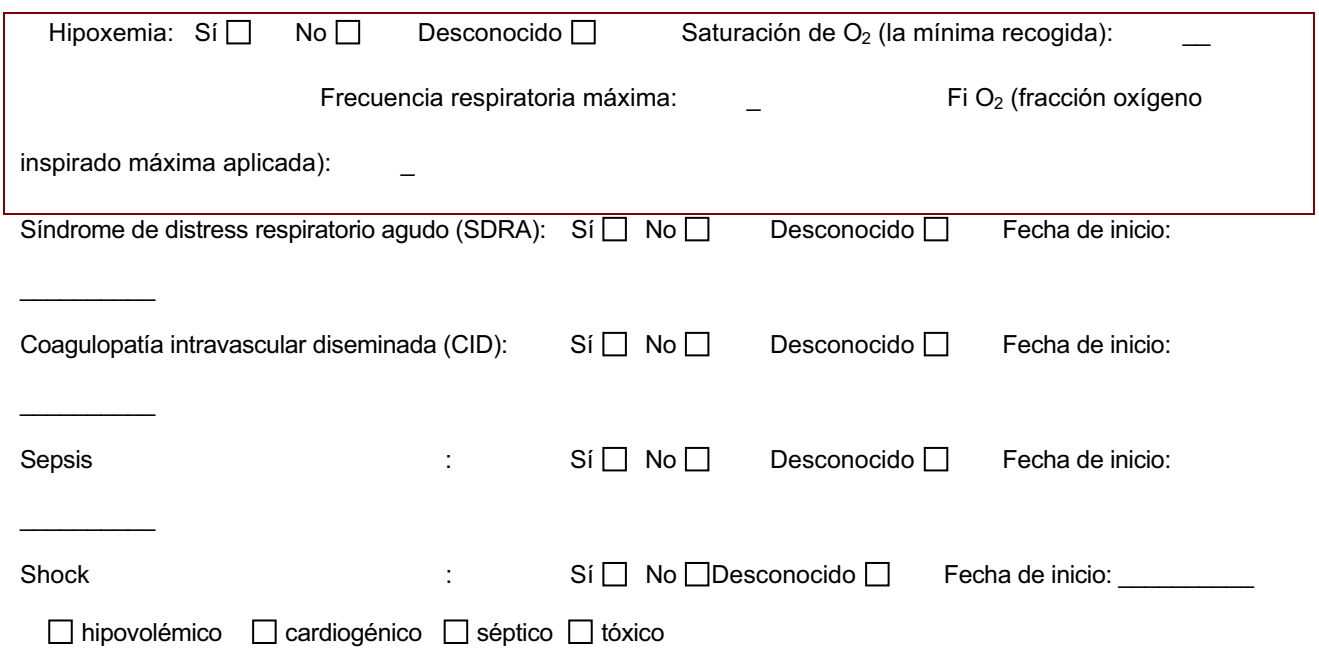


Patricia Santa-Olalla Peralta et al.

Alteración cardiaca/ cardiopatía

Sí $\square$ No $\square \quad$ Desconocido $\square$

Fecha de inicio:

Especificar:

Alteración función hepática:

Sí $\square$ No $\square$

Desconocido

Fecha de inicio:

Fracaso renal agudo:

Sí $\square$ No $\square$

Desconocido

Fecha de inicio:

Encefalitis/ Encefalopatía:

Sí $\square$ No $\square$

Desconocido

Fecha de inicio:

Otras:

Tratamiento de soporte en algún momento del proceso*

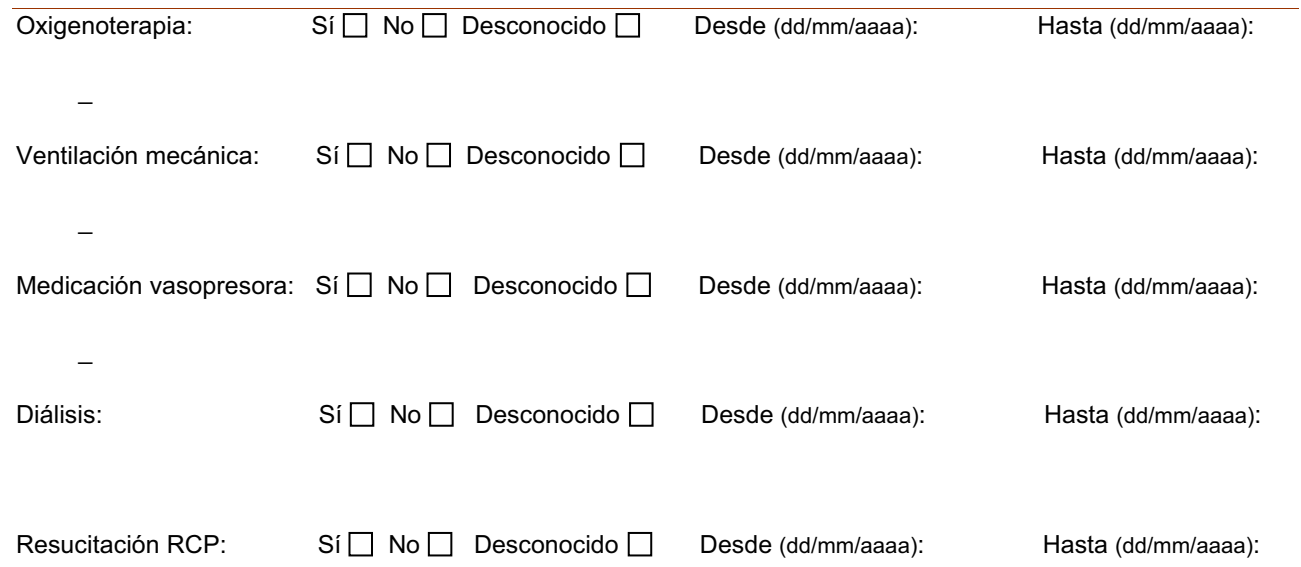

\section{Tratamiento antiviral}

¿Ha recibido tratamiento con antivirales? Sí $\square$ No $\square$ Desconocido $\square$

En caso afirmativo,

Nombre del fármaco 1:

Dosis:

$\mathrm{N}^{\circ}$ de días (dd/mm/aaaa):

Desde (dd/mm/aaaa):

Hasta (dd/mm/aaaa): 
CASOS DE INFECCIÓN POR GRIPE PANDÉMICA (H1N1) 2009 HOSPITALIZADOS EN CUIDADOS INTENSIVOS EN ESPAÑA..

Nombre del fármaco 2:

Dosis:

$\mathrm{N}^{\circ}$ de días (dd/mm/aaaa):

Desde (dd/mm/aaaa):

Hasta (dd/mm/aaaa):

\section{Estatus a la notificación?}

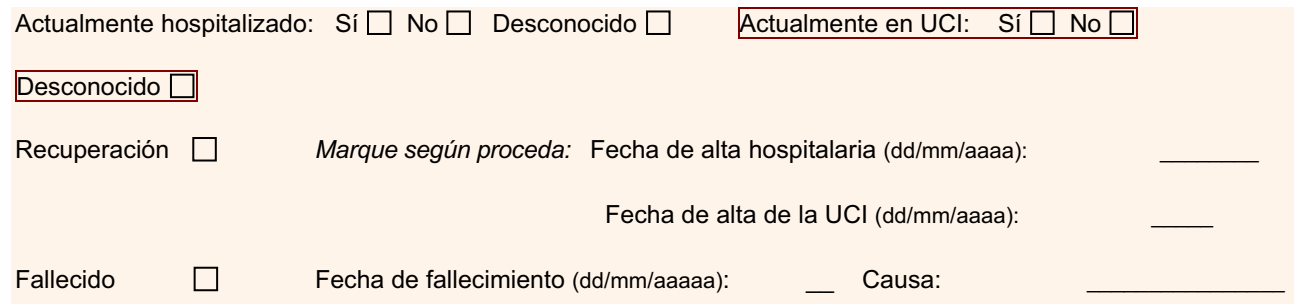

\section{Diagnóstico de laboratorio}

Técnica:

Fecha de confirmación (dd/mm/aaaa):

Laboratorio:

${ }^{2}$ Actualizar una vez finalizado el proceso 